\title{
Voice Control for an Industrial Robot as a Combination of Various Robotic Assembly Process Models
}

\author{
Svitlana Maksymova', Rami Matarneh ${ }^{2 *}$, Vyacheslav V. Lyashenko ${ }^{3}$, Nataliya V. Belova ${ }^{3}$ \\ ${ }^{1}$ Department of Computer-Integrated Technologies, Automation and Mechatronics, Kharkiv National University of Radio \\ Electronics, Kharkiv, Ukraine \\ ${ }^{2}$ Department of Computer Science, Prince Sattam Bin Abdulaziz University, Al-Kharj, Saudi Arabia \\ ${ }^{3}$ Department of Informatics, Kharkiv National University of Radio Electronics, Kharkiv, Ukraine \\ Email: *ramimatarneh@gmail.com
}

How to cite this paper: Maksymova, S., Matarneh, R., Lyashenko, V.V. and Belova, N.V. (2017) Voice Control for an Industrial Robot as a Combination of Various Robotic Assembly Process Models. Journal of Computer and Communications, 5, 1-15. https://doi.org/10.4236/jcc.2017.511001

Received: July 29, 2017

Accepted: September 1, 2017

Published: September 4, 2017

Copyright (c) 2017 by authors and Scientific Research Publishing Inc. This work is licensed under the Creative Commons Attribution International License (CC BY 4.0).

http://creativecommons.org/licenses/by/4.0/

\begin{abstract}
Models for the design of assembly processes are considered. Various models for the voice control of an industrial robot are considered: a logical model, semantic networks, a frame model and Petri nets. It is shown that this set of models allows describing the process of designing the technological process for an industrial robot. The logical model of the technological process allows you to define logical relationships. A model based on semantic networks describes the relationship between assembly units in a detail. This allows you to determine the order and method of registration, as well as the mutual orientation of assembly units in the product. The frame model provides the ability to streamline the execution of the build process. A model based on Petri nets allows one to describe the type and sequence of technological transitions. Based on the proposed models, a method of voice control for an industrial robot is developed. The basic principles of voice control for an industrial robot are considered.
\end{abstract}

\section{Keywords}

Robot, Voice Control, Frame Model, Petri Nets, Logic Model,

Semantic Nets, Robotic Assembly Processes

\section{Introduction}

Assembly as technological process is a part of production process. It is associated with qualitative transformation (changing) of production object. We have to notice assembly realization task is multi-variant. It is explained by the fact that for 
the same operation and all the process functions realization systems with different structures and functional elements (modules) may be used. Such systems have different technical and economic parameters. For this task solving it is expediently to use simulation methods and graph theory and search and optimization mathematical methods main positions. As a result, we can design optimal robotic assembly technological process and identify errors in robot control program before its using in industrial conditions. Using modeling we can develop collision free paths.

In [1] Zixiang Li, Qiuhua Tang, Li Ping Zhang propose to minimize energy consumption and cycle time using restarted simulated annealing algorithm. Marco Faber, SinemKuz, Marcel Ph. Mayer, Christopher M. Schlick in [2] use simulations in order to evaluate parameters, new assembly or planning strategies or the assembly of new products. In [3] authors present Taguchi optimization method in conjunction with simulation modeling in a new application for dynamic scheduling problems in robotic flexible assembly cells, in order to minimize total tardiness and number of tardy jobs. George Michalos, Konstantinos Kaltsoukalas, Panagiotis Aivaliotis, PlatonSipsas, Andreas Sardelis, George Chryssolouris [4] use semantic model representing the robot/resource skills along with the operations that a resource has to execute. In [5] authors write simulation-based technologies constitute a focal point of digital manufacturing solutions, since they allow for the experimentation and validation of different product, process and manufacturing system configurations. In [6] SongliangNiea, Yuwen Lib, GuoShuaia, Song Taoa, Fengfeng Xi propose method for modeling and analyzing the fatigue life of robots with flexible joints. Hod Lipson [7] uses simulation for soft robots. In [8] authors use frame model to facilitate as-built Building Information Model generation. Arne Wahrburg, Stefan Zeiss, Björn Matthias, Jan Peters, Hao Ding [9] propose to use modeling in order to create primitives that encapsulates the capabilities to coordinate, control and supervise an elementary robot task. At last in [10] autorspropese even powerful general-purpose robot simulation framework called V-REP that renders simulations and simulation models more accessible to a general-public, by reducing the simulation model deployment complexity.

In general case robotic assembly process includes next operations:

- robot has orientation with required accuracy on the specified assembly details surfaces;

- mating detail clamping, its move in working space to assembly device or base detail;

- mating detail orientation with required accuracy on base detail or device surface;

- details conjugation that are mutually oriented with required accuracy;

- completed details fixation.

Currently it is expediently to use robot voice control as computer-aided design (CAD) interactive interface implementation mean. It allows representing specific technological task features, to take into account equipment and robot 
functioning workspace characteristics, to provide corrections into technological transitions set, robotic system state operational control.

In [11] audio information is used for robot motion control. Authors in [12] integrate the industrial robot ABB IRB140 with the system for automatic speech recognition that has a task to recognize human speech and use it as a command to the robot, so the robot can manipulate the objects. Panagiota Tsarouchi, Sotiris Makris, George Chryssolouris [13] discuss process of learning by demonstration as well as the instructive systems is reviewed, focusing mainly on programming through visual guidance and imitation, voice commands and haptic interaction. In [14] authors propose approach that is distributed, fault tolerant and scalable, such that any recognition algorithm or language support can be added and used without any changes to the existing system. Alberto Poncela and Leticia Gallardo-Estrella [15] represent a human-robot interface to teleoperate a robotic platform via the user's voice. In [16] Somnath Kar, Ankit Jana, Debarshi Chatterjee, Dipayan Mitra use voice control technique to navigate the robot in various directions in the Cartesian plane. In [17] authors research industrial robot voice control in noisy environment. Carlos Mateo, Alberto Brunete, Ernesto Gambao, Miguel Hernando [18] use voice control to make easier to program tasks for industrial robots like polishing, milling or grinding. In [19] H. C. Fang, S. K. Ong, A. Y. C. Nee to use voice control for novel augmented reality based interface for interactive robot path and end-effector (EE) orientation planning. Adam Rogowski [20] proposes even Web-based remote robotized cells voice control. So we can say industrial robot voice control has plenty of advantages and may be used in different industrial fields.

\section{Modeling as a Decision-Making Tool}

A model is any image, analog, description, scheme, drawing, map, etc. of any object, process or phenomenon used as its substitute or representative. Each model reflects certain selected characteristics and neglects non-essential for this model. Work not with the object itself, but with its model allows to quickly and without material costs investigate its properties and behavior in certain situations. There are four main presentation forms: analytical, tabular, graphical and graphical. The analytical form represents a model in the form of a formula, an analytical expression, a set of analytical expressions. It is applied under certain model or object behavior laws. The graphical form uses models or data set representation in the form of curves, graphs, diagrams. The tabular form gives model or its characteristics representation in the form of one or a set of interrelated tables. The graph form is based on the representation of the model in the form of a graphical scheme called a graph.

Robotic assembly production processes design is difficult to be mathematically modeled, because it is based on technological rules using and often depends on subjective factors. But scientists try use different model for their goals achievement [4] [8] [21] [22] [23] [24] [25]. In [21] modeling is used for making 
logic and for evaluation of the control logic performance and the results. K. Abd, K. Abhary, R. Marian [22] used simulation for results evaluation. Models are often used to represent in a formalized way the structure, the behavior, and the requirements of the assembly systems [23]. In [24] authors propose to use fuzzy logic based model in order to predict surface roughness. George Pintzos, Nikolaos Nikolakis, Kosmas Alexopoulos, George Chryssolouris [26], Yanru Zhonga, Yuchu Qinb, Meifa Huangc, Wenlong Lub, Liang Chang [27], Mehmet Dogar, Ross A. Knepper, Andrew Spielberg, Changhyun Choi, Henrik I. Christensen, Daniela Rus [28], Q. Yanga, D. L. Wuc, H. M. Zhuc, J. S. Baoc, Z. H. Wei [29] and George Michalos, Konstantinos Kaltsoukalas, Panagiotis Aivaliotis, PlatonSipsas, Andreas Sardelis, George Chryssolouris [4] use semantic models for assembly simulation. Gong-dong Wang, Yao Yang, Wei Wang, L. V. Si-Chao [30], Jiaxiang Luo, Jiyin Liu, Yueming Hu [31] and L. Westover, J. Olearczyk, U. Hermann, S. Adeeb, Y. Mohamed [32] use frame models for assembly simulation. Hesuan $\mathrm{Hu}$, Meng $\mathrm{Chu}$ Zhou [33], Nai-Chieh Wei, I-Ming Chao, Chin-Jung Liu and, Hong Long Chen [34], Hesuan Hu, Mengchu Zhou, Zhiwu Li, Ying Tang [35], Yan Yang, Hesuan Hu, Yang Liu [36] and Hao Yue, Hesuan $\mathrm{Hu}$, Weimin $\mathrm{Wu}$, Hongye Su, Jihui Zhang [37] use Petri Nets for assembly simulation.

\subsection{Robotic Assembly Processes Logic Model}

As a result of mathematical models analysis assembly technological process design logical model is proposed.

In developing of assembly technological process design logical model we have to take into account next constructions features: all parts are limited in displacements in all directions, each item of the product is oriented towards other parts of this product and all parts of the product are interconnected. Any product construction may be assembled. Let us consider hinged elements mounting on a board. Let the circuit board require the installation of chips that can vary from minimum to maximum values: capacitors in the range from 0 to $i, 0$ to $j$ transistors, 0 to 1 resistors, 0 to $\mathrm{k}$ inductors and 0 to $\mathrm{m}$ diodes. For realization of technological processes implementations, it is suggested to formulate a set of basic technological rules, so we propose a form the main rules set, where each detail is characterized by certain parameters, which can be represented as follows:

$$
\text { parameters(name, square, dimension, mount_variant) }
$$

Mount variant takes into account which outputs contain a hinged element (planar or core). For radio electronic products assembly the feature of each element can be written as follows:

$$
\text { feature(name, [control_points_list]) }
$$

where [control_points_list $]=[\mathrm{cp} 1, \mathrm{cp} 2], \mathrm{cp} 1, \mathrm{cp} 2$ - the point of orientation of the element on the board.

Then assembly unit may be represented in next way: 
assembly_unit(number, board, [hinged_elements_list])

For radio electronic products assembly, let us formulate our proposed rules as follows:

Rule 1. Assembly unit may include different assembly units types (type1, type2, ...):

$$
\begin{aligned}
& \exists \mathrm{x} \exists \mathrm{y}(\operatorname{type}(\mathrm{x}, \text { board }) \wedge \operatorname{type}(\mathrm{y},[\text { hinged_elements_list }])) \\
& \rightarrow \exists \mathrm{u}(\operatorname{type}(\mathrm{u}, \text { assembly_unit }) \wedge \operatorname{contains}(\mathrm{u},[\mathrm{x}, \mathrm{y}])) .
\end{aligned}
$$

Rule 2. Base details have similar features (for example, holes), fastening elements-appropriate dimensions, that allow to connect base details (B) with other details (D):

$$
\begin{aligned}
& \exists \mathrm{u}(\operatorname{type}(\mathrm{u}, \text { assembly_unit }) \wedge \text { feature }(\mathrm{u},\{\mathrm{B}, \mathrm{D}\})) \\
& \rightarrow \text { assembly_unit_found }(\mathrm{u}, \mathrm{B}, \mathrm{D})
\end{aligned}
$$

Rule 3. Product is considered to be assembled when all its assembly rules are assembled. Assembly unit is considered to be assembled when all details included in it are founded.

From the model point of view we can consider assembly technological process. Assembly technological process start stage is base detail finding:

$$
\begin{aligned}
& \exists \mathrm{B} \exists \mathrm{D} \exists \mathrm{u}(\text { base _ found }(\mathrm{B}) \wedge \text { compatible_detail }(\mathrm{B}, \mathrm{D}) \\
& \wedge \text { assembly_unit_found }(\mathrm{u}, \mathrm{B}, \mathrm{D}) \wedge \text { assembled }(\text { и })) \rightarrow \text { process _ completed }
\end{aligned}
$$

Then we find detail that will be connected with the base detail (compatible part) and assembly unit that includes base and compatible detail.

Base detail is the detail with the biggest dimensions.

$$
\exists \mathrm{B}(\text { base _found }(\mathrm{B}) \vee \text { max _dimension }(\mathrm{B})) \rightarrow \text { base _found }(\mathrm{B})
$$

Detail compatible with base must have compatible features:

$$
\begin{aligned}
& \exists \mathrm{B} \exists \mathrm{D} \exists \mathrm{S}(\operatorname{detail}(\mathrm{B}) \wedge \operatorname{detail}(\mathrm{D}) \wedge \text { feature }(\mathrm{B}, \mathrm{S}) \wedge \text { feature }(\mathrm{D}, \mathrm{S})) \\
& \rightarrow \text { compatible_detail }(\mathrm{B}, \mathrm{D})
\end{aligned}
$$

Then it is necessary to determine assembly process sequence and details which will connect base and compatible details.

\subsection{Semantic Nets in Robotic Assembly Process Simulation}

For connotations between assembly units in product analysis we propose to represent assembly technological process using semantic net. Semantic net and its elements describe relations between assembly units. It is a directed graph with marked verticles and arcs. Verticles are mapped to objects (in our case details) and arcs are mapped to semantic relations between them. By the definition scheme, or relations intensional $\mathrm{Ri}$, is next pairs set:

$$
\operatorname{INT}(\mathrm{Ri})=\{\cdots,[\mathrm{Aj}, \mathrm{DOM}(\mathrm{Aj})], \cdots\},
$$

where $\mathrm{Ri}$-relations name; 
$\operatorname{DOM}(\mathrm{Aj})$ - domain $\mathrm{Aj}$, i.e. attribute values set $\mathrm{Aj}$ of relation $\mathrm{Ri}$

All domains union is an extensional of relation $\mathrm{Ri}$, i.e.

$$
\operatorname{EXT}(\mathrm{Ri})=\{\mathrm{F} 1, \cdots, \mathrm{Fp}\}
$$

where $\operatorname{Fk}(\mathrm{k}=1, \mathrm{p})$ - fact of relation Ri.

Fact is set by pairs "attribute-value" totality. They are called attributive pairs. In graphic form graph is a semantic net subgraph that has a star like structure. Subgraph root is a predicate type verticle. From subgraph verticle edges start marked as fact attributes names. They are directed to base set verticles that are these attributes values.

A fragment of the semantic product description network is shown in Figure 1. A model of a semantic network can be used at the initial stage of the product analysis and will determine the order and method of alignment in addition to the mutual orientation of assembly units in the product.

Thus, the developed semantic model of the manufacturing process assures the description of the relations between assembly units in the assembled product. Although the semantic network is designed to display the existence of semantic links between assembly units, the full description of the product seems rather cumbersome, even for simple products. Therefore, it seems advisable to use the semantic network model only to display individual nodes, including standardized in composition and technological execution.

\subsection{Robotic Assembly Processes Frame Model}

Since in assembly process there are often separate units assembly processes typical situations it is expediently to consider assembly technological process frame model.

For each assembly unit there are plenty of assembly schemes CD.

In particular, $\mathrm{CD}$ may be represented in next way:

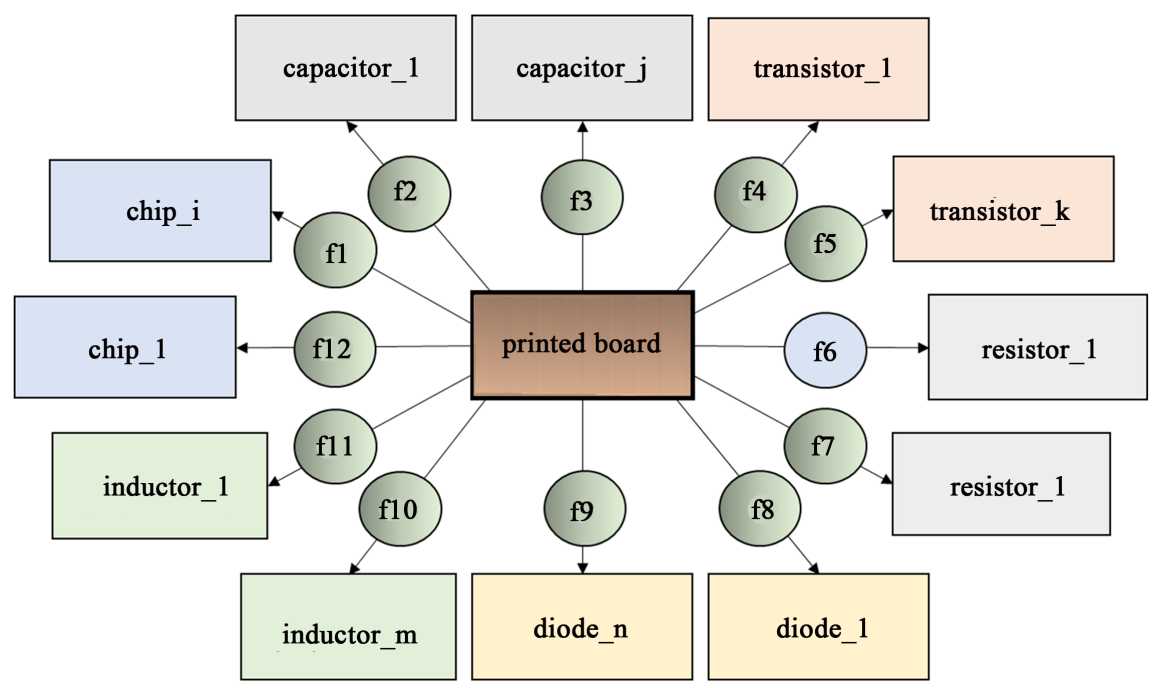

Figure 1. Semantic net fragment describing relation "Orientation". 


$$
\mathrm{CD}=\langle\mathrm{C}(\mathrm{D}) 1, \mathrm{C}(\mathrm{D}) 2, \cdots, \mathrm{C}(\mathrm{D}) \mathrm{N}\rangle
$$

where $\mathrm{CD}$-assembly process schemes plurality,

$\mathrm{C}(\mathrm{D}) \mathrm{i}-$ possible assembly process scheme,

$\mathrm{N}-$ possible assembly process scheme number.

In its turn $C(D)$ may be written in next form:

$$
C(D)=\langle d a, d b, \cdots, d m\rangle
$$

where D—necessary assembly operations plurality;

di D-separate assembly operation;

$\mathrm{m}$-necessary assembly operations number.

Each separate assembly operation is performed by specific instrument. It is also described by start and finish positions of assembled detail. It can be written in next way:

$$
\mathrm{di}=\langle\mathrm{I}, \mathrm{ndet} 1, \mathrm{ndet} 2, \mathrm{kdet} 1, \mathrm{kdet} 2\rangle
$$

where I-instrument;

ndet1-detail1 start position;

ndet2-detail2 start position;

$k \operatorname{det} 1$-detail1 finish position;

kdet2-detail2 finish position.

In scheme C(D)I may be typical assembly process sub-sequence $\langle\mathrm{di}, \mathrm{dj}, \mathrm{dk}\rangle$, that will represent typical assembly technological operation. So, it is a technological operation frame.

Example of frame of typical technological operations accentuation in technological process structure is shown on Figure 2 (sequences (di, dj, dk) and (da, $\mathrm{db})$ ).

Let us notice for every elements type mounting on printed board it is necessary to implement actions totality-technological process sub-sequences. Frame "Diodes_mounting" contains operations that are necessary for diodes mounting: operation of taking the diode from the store, placing the diode on the necessary place on the printed circuit board, orienting it relative to the control points, and the installation itself. Similarly, frames are allocated for each type of mounted elements: chips, transistors, capacitors, resistors, inductors.

When analyzing the technological processes of the assembly, it is necessary to find typical sub-sequences and streamline the assembly process according to the

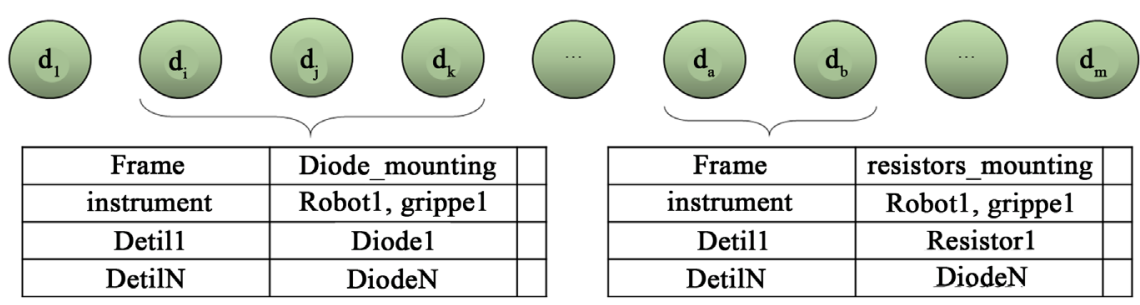

Figure 2. Example of frame of typical technological operations accentuation in technological process structure. 
criteria of saving time, materials, equipment. To fulfill these criteria, it is advisable to select sub-sequences that can be executed in parallel, minimize the need for reorientation of the robot and parts, as well as tool changes during the assembly process.

Examination of the frame model allows us to make the following conclusion: when assembly technological process is designing, the frame model is suitable for describing typical sub-sequences of technological processes, individual technological operations and transitions. Even in a completely new product, it is possible to have typical assembly units for which there will be an appropriate frame in the structure of the process planning system that describes assembly process element-a kind of micro-know-how for an individual node, transition or operation.

\subsection{Petri Nets in Robotic Assembly Processes Modeling}

It is convenient to use Petri nets when robotic production technological processes are designing. The application of Petri nets can be viewed in two ways. On the one hand, with the help of the Petri net, it is possible to represent the detailed structure of technological transitions of the designed assembly technological process. It is assumed that the sequence of the assembly process has already been determined and can be developed either with the help of Petri nets or with the help of other models. On the other hand, the model of Petri nets can be the basis for technological process design with initially uncertain character of the transitions. In this case, all possible assembly process variants may be described by the sequence of nodes-assembly elements and subassemblies. The choice of a particular sequence can be determined by means of a logical model and evaluated using definiteness coefficients.

Let's consider the simulation of the assembly robotic complex work using a Petri net. Assembly robotic complex work begins with industrial robot turn on. Further, under the condition of the performed turning on, the manipulator is checked in the start position (at point $1^{\prime}$ ). At the next step, the manipulator is moved to the location of detail 2 (details store). After that, the detail is clamped with a grip, after which it is transferred to the installation point (destination 1). The next step is to install the detail in the required position and release the gripping device. The manipulator is moved to the destination 1 . The number of installed details is incremented, all details are checked, and if not, the manipulator moves to the required point 2 (details store). The cycle is repeated until all details are mount, after which the manipulator arm is moved to the starting point 1 ', and the robot turns off.

Petri net can be used in determining the order of the assembly process in the robotic complex (Figure 3).

In Figure 3 variables take the following values:

$\mathrm{x} 0$-robotic complex on, $\mathrm{x} 1$-industrial robot manipulator at the starting point $1^{\prime}$. 


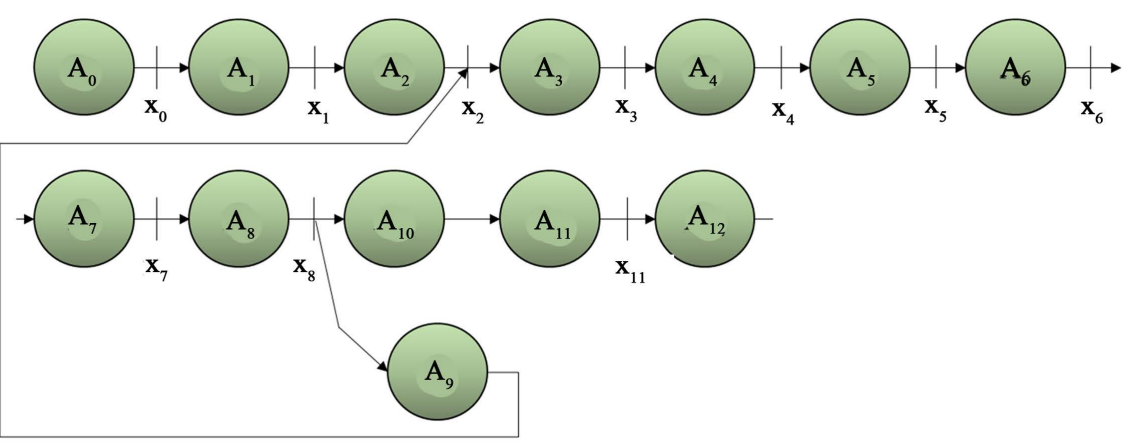

Figure 3. Petri net for assembly robotic complex functioning.

$\mathrm{x} 2$-industrial robot manipulator at the required point 2 .

$\mathrm{x} 3$ - the part is clamped by industrial robot gripper device.

$\mathrm{x} 4$-industrial robot manipulator at the destination 1 .

$\mathrm{x} 5$ - detail.

$\mathrm{x} 6$ - the detail is unclenched by industrial robot gripper device.

$\mathrm{x} 7$-industrial robot manipulator at the destination 1 .

$\mathrm{x} 8-\mathrm{i}=\mathrm{i}+1$.

$\mathrm{x} 9-\mathrm{i}<\mathrm{n}+1$.

$\mathrm{x} 10-\mathrm{i}=\mathrm{n}+1$.

$\mathrm{x} 11$-industrial robot manipulator at the starting point1'.

A0-is robotic complex turn on.

A1-is the movement of industrial robot manipulator to the start point 1'.

A2-is the movement of industrial robot manipulator PR to the required point 2.

A3-is work piece capture by robot.

A4-moving the manipulator PR to the point 1.

A5-setting the part.

A6-expanding the workpiece by the robot.

A7-moving industrial robot manipulator to the point 1 .

$\mathrm{A} 8-\mathrm{i}=\mathrm{i}+1$.

A9- $\mathrm{i}<\mathrm{n}+1$.

$\mathrm{A} 10-\mathrm{i}=\mathrm{n}+1$.

A11-move industrial robot manipulator to the starting point 1 '.

A12-turn off the robot. It is proposed to use the Petri net to analyze the robot's technological process to detect errors, the presence of looping and non-rational movements of the robot's manipulator. In the event that these situations are detected, it is necessary to correct the process of the robot directly to avoid errors in the robot application program development.

Thus, the model allows to describe detailed the nature of technological transitions in assembly robotic complex technology design. It is also reasonable to use the Petri net in determining the order of the assembly process in the robotic complex, eliminating possible errors, looping and inefficient movements of the robot manipulator. Given the multivariance of the assembly technology design 
process and the need to evaluate each option, we should also talk about the applicability of the approach of fuzzy Petri nets.

\section{Voice Control Method for an Industrial Robot}

In the CAD (computer-aided design) development for various purposes, the necessary stage is technological processes models selection, which depends on the modeled object structure, its properties, and the application of the various data processing facilities. The nature of the models determines the essence of design methods.

Robotic production technological processes design is most often performed in off-line mode. At the initial stages of the design, the sets of working points of robot trajectories are memorized. Next, each set of trajectories is associated with a set of movement commands. Between the move commands, the manipulation of working objects is usually placed.

Models set presented above must be used as a sequence. At first the product is analyzed using rules and positions represented in logical model. Then we use semantic model in order to understand connotations between details. After analyzing connotations we have to check standard situations presence using frame. This stage may simplify developing technological process. And next we have to form robot's technological operations and transitions. For this it is expediently to use model based on Petri nets. So all these models are used in order to form sequence of industrial robot actions.

Let us consider voice control method used after product analysis based on models sequence presented above. It is a description of the set of techniques and operations used in robotic production assembly technological processes automated design.

In particular, it provides that the design of the assembly process using voice control for an industrial robot is based on the following principles.

1) Assembly units placement in the robot workspace determines the nature and sequence of technological and auxiliary transitions. In terms of predicate logic, this expression can be written in next way:

$$
\begin{aligned}
& \forall \mathrm{x}(\operatorname{type}(\mathrm{x} \text {, assembly_unit })) \exists \mathrm{y}(\operatorname{type}(\mathrm{y} \text {, technological_transition })) \\
& \exists r(\text { type }(\mathrm{r} \text {, rule })) \rightarrow \exists \overrightarrow{\mathrm{t}}(\operatorname{type}(\overrightarrow{\mathrm{t}} \text {, technological_transitions_sequence })) .
\end{aligned}
$$

2) Coordinates of any point, any command for moving a manipulator is given by a voice in a limited natural language. This expression can be represented in the following form:

$$
\begin{aligned}
& \forall \mathrm{p}(\text { type }(\text { p, point })) \forall \mathrm{c}(\text { type }(\mathrm{c}, \text { command })) \\
& \exists \mathrm{vp}(\text { type }(\mathrm{vp}, \text { voice_presentation })) .
\end{aligned}
$$

3) Commands, the sequence of which provides the fulfillment of the goals of technological or auxiliary transitions, are combined into meta-commands. This expression can be written in next way: 


$$
\begin{aligned}
& \exists \mathrm{c}(\operatorname{type}(\mathrm{c}, \text { command })) \mathrm{c} \in \mathrm{y}(\text { type }(\mathrm{y} \text {, technological_transition })) \\
& \wedge \mathrm{y} \in \mathrm{T}(\text { type }(\mathrm{T} \text {, typical_technological_transition })) \\
& \rightarrow \exists \mathrm{mc}(\operatorname{type}(\mathrm{mc}, \text { meta }- \text { command })) .
\end{aligned}
$$

4) Sequences of control commands, given by voice, realize separate technological or auxiliary transitions, separate technological operations and form the technological process. This provision is represented by the following group of formal expressions:

$$
\begin{aligned}
& \exists \operatorname{vp}(\operatorname{type}(\text { vp, voice_presentation })) \\
\rightarrow & \exists \overrightarrow{\mathrm{VP}}(\operatorname{type}(\overrightarrow{\mathrm{VP}} \text {, voice_commands_sequence })), \\
\exists \overrightarrow{\mathrm{VP}} \rightarrow & \exists \overrightarrow{\mathrm{t}}(\operatorname{type}(\overrightarrow{\mathrm{t}} \text {, technological_transitions_sequence })), \\
\exists \overrightarrow{\mathrm{t}} \rightarrow & \exists \overrightarrow{\mathrm{to}}(\operatorname{type}(\overrightarrow{\mathrm{to}} \text {, technological_operations_sequence })), \\
& \overrightarrow{\mathrm{to}} \rightarrow \overrightarrow{\mathrm{tp}}(\operatorname{type}(\overrightarrow{\mathrm{tp}}, \text { technological_process })) .
\end{aligned}
$$

5) Commands voice input application order is established on the basis of the assembly drawing analysis and is determined by the above models of assembly products and technological processes representation.

6) Information voice input ensures the work for information input subsystem in the $\mathrm{CAD}$ of robotic production control programs.

\section{Conclusions}

In the article, robotic production assembly technological processes design models are considered. The formal representation of assembly processes is based on the general representation of the assembly detail as an ordered set of assembly units. The nature of ordering is determined by the design intent of the assembly detail, taking into account the interaction of assembly units, their dimensional relationships, formal and informal logical patterns of technological processes design.

Based on the properties of assembly technological processes design, technological process logical model was developed. Technological process model based on semantic networks is proposed, which describes the relationship between assembly units in a detail. To identify typical situations in assembly process sequence, technological process frame model was developed, which makes it possible to order the assembly process execution. Assembly technological process model based on Petri nets is proposed, which allows describing in detail the type and sequence of technological transitions.

The specified set of models will allow describing technological process design process from different points of view and taking into account voice control using, provide a holistic description and prepare the basis for the practical imple- 
mentation of the voice control subsystem in the CAD robot technological process system.

Based on the proposed models, a voice control method for an industrial robot is developed, the main principles of which are given in the paper.

It should also be noted that using the ideology of image processing or wavelet analysis methodology [38]-[45] together with voice control of the robot will create new applications for technological processes.

\section{References}

[1] Li, Z., Tang, Q. and Zhang, L. (2016) Minimizing Energy Consumption and Cycle Time in Two-Sided Robotic Assembly Line Systems Using Restarted Simulated Annealing Algorithm. Journal of Cleaner Production, 135, 508-522.

https://doi.org/10.1016/j.jclepro.2016.06.131

[2] Faber, M., Kuz, S., Mayer, M.P. and Schlick, C.M. (2013) Design and Implementation of a Cognitive Simulation Model for Robotic Assembly Cells. International Conference on Engineering Psychology and Cognitive Ergonomics, Springer, Berlin, Heidelberg, 205-214.

[3] Abd, K., Abhary, K. and Marian, R. (2014) Simulation Modelling and Analysis of Scheduling in Robotic Flexible Assembly Cells Using Taguchi Method. International Journal of Production Research, 52, 2654-2666. https://doi.org/10.1080/00207543.2013.867082

[4] Michalos, G., Kaltsoukalas, K., Aivaliotis, P., Sipsas, P., Sardelis, A. and Chryssolouris, G. (2014) Design and Simulation of Assembly Systems with Mobile Robots. CIRP Annals-Manufacturing Technology, 63, 181-184. https://doi.org/10.1016/j.cirp.2014.03.102

[5] Mourtzis, D., Papakostas, N., Mavrikios, D., Makris, S. and Alexopoulos, K. (2015) The Role of Simulation in Digital Manufacturing: Applications and Outlook. International Journal of Computer Integrated Manufacturing, 28, 3-24. https://doi.org/10.1080/0951192X.2013.800234

[6] Nie, S., Li, Y., Shuai, G., Tao, S. and Xi, F. (2016) Modeling and Simulation for Fatigue Life Analysis of Robots with Flexible Joints under Percussive Impact Forces. Robotics and Computer-Integrated Manufacturing, 37, 292-301. https://doi.org/10.1016/j.rcim.2015.04.001

[7] Lipson, H. (2014) Challenges and Opportunities for Design, Simulation, and Fabrication of Soft Robots. Soft Robotics, 1, 21-27. https://doi.org/10.1089/soro.2013.0007

[8] Feng, C., Xiao, Y., Willette, A., McGee, W. and Kamat, V.R. (2015) Vision Guided Autonomous Robotic Assembly and As-Built Scanning on Unstructured Construction Sites. Automation in Construction, 59, 128-138. https://doi.org/10.1016/j.autcon.2015.06.002

[9] Wahrburg, A., Zeiss, S., Matthias, B., Peters, J. and Ding, H. (2015). Combined Pose-Wrench and State Machine Representation for Modeling Robotic Assembly Skills. 2015 IEEE/RSJ International Conference on Intelligent Robots and Systems (IROS), 852-857. https://doi.org/10.1109/IROS.2015.7353471

[10] Rohmer, E., Singh, S.P. and Freese, M. (2013) V-REP: A Versatile and Scalable Robot Simulation Framework. 2013 IEEE/RSJ International Conference on Intelligent Robots and Systems (IROS), 1321-1326. https://doi.org/10.1109/IROS.2013.6696520

[11] Pleshkova, S., Bekiarski, A., Dehkharghani, S.S. and Peeva, K. (2015) Perception of 
Audio Visual Information for Mobile Robot Motion Control Systems. In: Computer Vision in Control Systems-2, Springer International Publishing, 135-167. https://doi.org/10.1007/978-3-319-11430-9_6

[12] Tasevski, J., Nikolić, M. and Mišković, D. (2013) Integration of an Industrial Robot with the Systems for Image and Voice Recognition. Serbian Journal of Electrical Engineering, 10, 219-230. https://doi.org/10.2298/SJEE1301219T

[13] Tsarouchi, P., Makris, S. and Chryssolouris, G. (2016) Human-Robot Interaction Review and Challenges on Task Planning and Programming. International Journal of Computer Integrated Manufacturing, 29, 916-931. https://doi.org/10.1080/0951192X.2015.1130251

[14] Gupta, M., Verma, P., Bhattacharya, T. and Das, P.K. (2015) A Mobile Agents Based Distributed Speech Recognition Engine for Controlling Multiple Robots. In: Proceedings of the 2015 Conference on Advances in Robotics, ACM, New York, 28. https://doi.org/10.1145/2783449.2783477

[15] Poncela, A. and Gallardo-Estrella, L. (2015) Command-Based Voice Teleoperation of a Mobile Robot via a Human-Robot Interface. Robotica, 33, 1-18. https://doi.org/10.1017/S0263574714000010

[16] Kar, S., Jana, A., Chatterjee, D., Mitra, D., Banerjee, S., Kundu, D. and Gupta, S.D. (2015) Image Processing Based Customized Image Editor and Gesture Controlled Embedded Robot Coupled with Voice Control Features. Image, 6, 91-96. https://doi.org/10.14569/IJACSA.2015.061113

[17] Silaghi, H., Rohde, U., Spoială, V., Silaghi, A., Gergely, E. and Nagy, Z. (2014) Voice Command of an Industrial Robot in a Noisy Environment. 2014 International Symposium on Fundamentals of Electrical Engineering, 1-5. https://doi.org/10.1109/ISFEE.2014.7050596

[18] Mateo, C., Brunete, A., Gambao, E. and Hernando, M. (2014) Hammer: An Android Based Application for End-User Industrial Robot Programming. 2014 IEEE/ ASME 10 th International Conference on Mechatronic and Embedded Systems and Applications, 1-6. https://doi.org/10.1109/MESA.2014.6935597

[19] Fang, H.C., Ong, S.K. and Nee, A.Y.C. (2014) A Novel Augmented Reality-Based Interface for Robot Path Planning. International Journal on Interactive Design and Manufacturing, 8, 33-42. https://doi.org/10.1007/s12008-013-0191-2

[20] Rogowski, A. (2013) Web-Based Remote Voice Control of Robotized Cells. Robotics and Computer-Integrated Manufacturing, 29, 77-89.

[21] Michalos, G., Sipsas, P., Makris, S. and Chryssolouris, G. (2016) Decision Making Logic for Flexible Assembly Lines Reconfiguration. Robotics and Computer-Integrated Manufacturing, 37, 233-250.

[22] Abd, K., Abhary, K. and Marian, R. (2013) A Methodology for Scheduling Robotic Flexible Assembly Cells Using Fuzzy Logic and Simulation. Proceedings of the World Congress on Engineering, Vol. 1, London, 3-5 July 2013.

[23] Thramboulidis, K. (2016) An Open Distributed Architecture for Flexible Hybrid Assembly Systems: A Model-Driven Engineering Approach. The International Journal of Advanced Manufacturing Technology, 85, 1449-1460. https://doi.org/10.1007/s00170-015-8064-4

[24] Barzani, M.M., Zalnezhad, E., Sarhan, A.A., Farahany, S. and Ramesh, S. (2015) Fuzzy Logic Based Model for Predicting Surface Roughness of Machined Al-Si-Cu-Fe Die Casting Alloy Using Different Additives-Turning. Measurement, 61, 150-161.

[25] Fattahi, A., Elaoud, S., SadeqiAzer, E. and Turkay, M. (2014) A Novel Integer Programming Formulation with Logic Cuts for the U-Shaped Assembly Line Balancing 
Problem. International Journal of Production Research, 52, 1318-1333. https://doi.org/10.1080/00207543.2013.832489

[26] Pintzos, G., Nikolakis, N., Alexopoulos, K. and Chryssolouris, G. (2016) Motion Parameters Identification for the Authoring of Manual Tasks in Digital Human Simulations: An Approach Using Semantic Modelling. Procedia CIRP, 41, 752-758.

[27] Zhong, Y., Qin, Y., Huang, M., Lu, W. and Chang, L. (2014) Constructing a Meta-Model for Assembly Tolerance Types with a Description Logic Based Approach. Computer-Aided Design, 48, 1-16.

[28] Dogar, M., Knepper, R.A., Spielberg, A., Choi, C., Christensen, H.I. and Rus, D. (2016) Towards Coordinated Precision Assembly with Robot Teams. In: Experimental Robotics, Springer International Publishing, 655-669.

https://doi.org/10.1007/978-3-319-23778-7_43

[29] Yang, Q., Wu, D.L., Zhu, H.M., Bao, J.S. and Wei, Z.H. (2013) Assembly Operation Process Planning by Mapping a Virtual Assembly Simulation to Real Operation. Computers in Industry, 64, 869-879.

[30] Wang, G.D., Yang, Y., Wang, W. and Si-Chao, L.V. (2016) Variable Coefficients Reciprocal Squared Model Based on Multi-Constraints of Aircraft Assembly Tolerance Allocation. The International Journal of Advanced Manufacturing Technology, 82, 227-234. https://doi.org/10.1007/s00170-015-7299-4

[31] Luo, J., Liu, J. and Hu, Y. (2017) An MILP Model and a Hybrid Evolutionary Algorithm for Integrated Operation Optimisation of Multi-Head Surface Mounting Machines in PCB Assembly. International Journal of Production Research, 55, 145-160. https://doi.org/10.1080/00207543.2016.1200154

[32] Westover, L., Olearczyk, J., Hermann, U., Adeeb, S. and Mohamed, Y. (2014) Analysis of Rigging Assembly for Lifting Heavy Industrial Modules. Canadian Journal of Civil Engineering, 41, 512-522. https://doi.org/10.1139/cjce-2013-0192

[33] Hu, H. and Zhou, M. (2015) A Petri Net-Based Discrete-Event Control of Automated Manufacturing Systems with Assembly Operations. IEEE Transactions on Control Systems Technology, 23, 513-524. https://doi.org/10.1109/TCST.2014.2342664

[34] Wei, N.C., Chao, I.M., Liuand, C.J. and Chen, H.L. (2014) Applying Branch-and-Bound and Petri Net Methods in Solving the Two-Sided Assembly Line Balancing Problem. World Academy of Science, Engineering and Technology, International Journal of Mechanical, Aerospace, Industrial, Mechatronic and Manufacturing Engineering, 8 , 136-141.

[35] Hu, H., Zhou, M., Li, Z. and Tang, Y. (2013) Deadlock-Free Control of Automated Manufacturing Systems with Flexible Routes and Assembly Operations Using Petri Nets. IEEE Transactions on Industrial Informatics, 9, 109-121.

https://doi.org/10.1109/TII.2012.2198661

[36] Yang, Y., Hu, H. and Liu, Y. (2015) A Petri Net-Based Distributed Control of Automated Manufacturing Systems with Assembly Operations. 2015 IEEE International Conference on Automation Science and Engineering, 1090-1097. https://doi.org/10.1109/CoASE.2015.7294244

[37] Yue, H., Hu, H., Wu, W., Su, H. and Zhang, J. (2017) Polynomial-Complexity Supervisory Control for Flexible Assembly Systems Based on Petri Nets. International Journal of Computer Integrated Manufacturing, 1-16. https://doi.org/10.1080/0951192X.2017.1335436

[38] Lyashenko, V., Matarneh, R., Kobylin, O. and Putyatin, Y. (2016) Contour Detection and Allocation for Cytological Images Using Wavelet Analysis Methodology. 
International Journal of Advance Research in Computer Science and Management Studies, 4, 85-94.

[39] Lyashenko, V., Matarneh, R. and Kobylin, O. (2016) Contrast Modification as a Tool to Study the Structure of Blood Components. Journal of Environmental Science, Computer Science and Engineering \& Technology, 5, 150-160.

[40] Lyashenko, V.V., Matarneh, R. and Deineko, Z.V. (2016) Using the Properties of Wavelet Coefficients of Time Series for Image Analysis and Processing. Journal of Computer Sciences and Applications, 4, 27-34.

[41] Ahmad, M.A., Lyashenko, V.V., Deineko, Z.V., Baker, J.H. and Ahmad, S. (2017) Study of Wavelet Methodology and Chaotic Behavior of Produced Particles in Different Phase Spaces of Relativistic Heavy Ion Collisions. Journal of Applied Mathematics and Physics, 5, 1130. https://doi.org/10.4236/jamp.2017.55100

[42] Lyashenko, V., Babker, A. and Lyubchenko, V. (2017) Wavelet Analysis of Cytological Preparations Image in Different Color Systems. Open Access Library Journal, 4, $1-9$.

[43] Lyashenko, V.V., Ahmad, M.A., Deineko, Z.V. and Rasool, M.H. (2017) Methodology of Wavelets in Relativistic Heavy Ion Collisions in One Dimensional Phase Space. Journal of High Energy Physics, 3, 254-266.

[44] Lyashenko, V.V., AMAaa, B. and Kobylin, O.A. (2016) Using the Methodology of Wavelet Analysis for Processing Images of Cytology Preparations. National Journal of Medical Research, 6, 98-102.

[45] Lyashenko, V.V., Babker, A.M.A.A. and Kobylin, O.A. (2016) The Methodology of Wavelet Analysis as a Tool for Cytology Preparations Image Processing. Cukurova Medical Journal, 41, 453-463. https://doi.org/10.17826/cukmedj.237468

Submit or recommend next manuscript to SCIRP and we will provide best service for you:

Accepting pre-submission inquiries through Email, Facebook, LinkedIn, Twitter, etc. A wide selection of journals (inclusive of 9 subjects, more than 200 journals)

Providing 24-hour high-quality service

User-friendly online submission system

Fair and swift peer-review system

Efficient typesetting and proofreading procedure

Display of the result of downloads and visits, as well as the number of cited articles

Maximum dissemination of your research work

Submit your manuscript at: http://papersubmission.scirp.org/

Or contact jcc@scirp.org 